\title{
Astrobiology in the Developing World
}

\section{Chandra Wickramasinghe $\mathbf{N}^{\star 1,2,3}$}

${ }^{1}$ Buckingham Centre for Astrobiology (BCAB), Buckingham University, UK

${ }^{2}$ Institute for the Study of Panspermia and Astroeconomics, Gifu, Japan

${ }^{3}$ University of Peradeniya, Peradeniya, Sri Lanka

*Corresponding author: Wickramasinghe NC, Buckingham Centre for Astrobiology (BCAB), Buckingham University, UK, Tel: +44-777-838-9243; E-mail: ncwick@gmail.com

Rec date: September 07, 2015; Acc date: September 09, 2015; Pub date: September 11, 2015

Copyright: $\odot 2015$ Chandra Wickramasinghe N, et al. This is an open-access article distributed under the terms of the Creative Commons Attribution License, which permits unrestricted use, distribution, and reproduction in any medium, provided the original author and source are credited.

\section{Editorial}

The perception that astrobiology is reserved for the richer nations of the world may have been dispelled by events that took place last month (August 21-23rd) in Sri Lanka. An international conference held at the University of Peradeniya announced the formal inauguration of a new Research Centre for Astrobiology attached to that University. There are 15 national Universities in Sri Lanka with well-equipped science laboratory facilities. There are also several dedicated research institutes for various disciplines of which SLINTEC (Sri Lanka Institute of Nanotechnology) is preeminent. Within these institutions there is considerable local expertise in microbiology, geology and nanotechnology among other scientific disciplines, all of which could be harnessed to address astrobiological questions.

To begin with the new Centre will be a virtual centre combining local expertise with overseas contacts, but the expectation is that it will turn into a real physical centre of excellence in astrobiology within a few years. Sri Lanka's interest in astrobiology may well have been sparked off by a series of natural events that occurred in the island in 2013. In December that year a meteorite fall and an episode of red rain brought the island into the focus of international astrobiology news. Whilst the origin of both the red rain cells and the meteorite are still a matter of controversy, these events nevertheless contributed to a rapidly growing interest in astrobiology.

Astrobiology is a subject that seeks to answer the age-old questions: where did we come from? Who are we? Where are we going? This discipline must surely be seen as part of our human heritage and made accessible to every country. Research in several areas related to astrobiology is relatively inexpensive and well within the reach of even technologically less advanced nations. Moreover, astrobiology has an enormous outreach potential that can serve to stimulate young people's interest in science. 